\title{
"A guerra que vai acabar com todas as guerras": o Brasil na Primeira Grande Guerra - a mobilização da sociedade e o engajamento da Marinha - 1917 - 1918
}

\author{
"The war to end all wars"- Brazil in the First World War - social mobilization and Naval \\ engagement-1917-1918
}

"Guerra que terminar todas las guerras": Brasil en la Primera Guerra Mundial - la movilización de la sociedad y participación de la Marina de guerra - 1917 - 1918

Johny Santana deAraújo*

\section{Resumo}

O presente artigo pretende tratar sobre a mobilização da sociedade e do aparato naval brasileiro no ano de 1918, como resposta do governo do presidente Wenceslau Brás à agressão alemã contra os navios mercantes brasileiros em 1917, além de observar quais foram as providencias tomada no sentido de organizar uma força naval efetiva denominada Divisão Naval de Operações de Guerra (DNOG) a fim de patrulhar a costa atlântica do norte da África.

Palavras-chave: Primeira Guerra Mundial. Mobilização. Marinha Brasileira.
Graduado em História Bacharelado pela Universidade Federal do Maranhão (2001), graduação em História Licenciatura Plena pela Universidade Federal do Maranhão (2004), Mestrado em História do Brasil pela Universidade Federal do Piauí (2005) Doutorado em História Social pela Universidade Federal Fluminense (2009). É Professor da Universidade Federal do Piauí e Membro do Programa de Pós-graduação em História do Brasil. Desenvolve pesquisas com ênfase em História do Brasil. Atuando principalmente nos seguintes temas: Formação do Estado Nação, História Militar, Forças Armadas do Século XIX ao XXI, História Política e História das Relações Internacionais, Relações Sociais, Politicas e Econômicas no Piauí do Século XIX, Escravidão no Brasil do Século XIX, Imprensa no Brasil do Século XIX. É líder do Grupo de Pesquisa: Núcleo de História, Memória, Sociedade e Política (cadastrado no CNPq). E-mail: johny@oi.com.br

Recebido em 24/03/2014 - Aprovado em 01/10/2014 http://dx.doi.org/10.5335/hdtv.14n.2.4575 


\section{Os ecos da guerra que chegaram ao Brasil}

Em agosto de 1914, chegavam ao Brasil as primeiras notícias sobre a guerra na Euro$\mathrm{pa}^{1}{ }^{1}$ multiplicavam-se as edições dos jornais e das revistas e alguns publicavam que esta seria, segundo Munhoz: "A guerra que vai acabar com todas as outras guerras" (1980, p. 33).

Três anos depois de iniciada a guerra na Europa, ou seja, no ano de 1917, a posição do Governo brasileiro ainda era a de neutralidade. Porém, a guerra na Europa havia provocado uma série de fortes debates em alguns setores da sociedade brasileira, sobretudo nos meios intelectuais.

Muitos desses intelectuais tinham natural simpatia pela cultura francesa e, de uma forma geral, a maioria das pessoas dos grandes centros urbanos também nutria simpatia pela causa francesa, graças à ação dos jornais (TAVARES, 1979). Foram poucos os que se colocaram ao lado dos alemães. Um dos maiores defensores dos aliados foi o crítico literário José Veríssimo, em outros casos houve os discordantes como foi o caso do ministro das Relações Exteriores Lauro Muller que era a favor da Alemanha, sobretudo por ser descendente de alemães, fato que o levou a deixar a pasta das relações exteriores, sendo substituído por Nilo Peçanha, mais afinado com os Estados Unidos (BUENO, 2003, p. 460).

A guerra na Europa já vinha estimulando as discussões de espírito nacionalista, e desde 1916, o poeta Olavo Bilac lançou-se à organização de uma entidade chamada "Liga de Defesa Nacional" cujo caráter era cívico-patrióta e lutava pela implantação do serviço militar obrigatório e pela participação do Brasil no conflito. ${ }^{2}$

Outras figuras de renome da sociedade literária na época como o maranhense Coelho
Neto e empresários como Roberto Simoensen e Jorge Street faziam parte da Liga. A Liga de Defesa Nacional promovia encontros e conferências nos quais se discutia sobre temas como "A ideia da guerra" e sucessivas cerimônias de cunho cívico-patrióticas aconteciam onde se hasteava a bandeira do Brasil, sob execução do hino nacional (DULLES, 1977, p. 40).

A política de neutralidade do governo Venceslau Brás rendeu, entre outras coisas, uma série de sátiras das revistas populares, ${ }^{3}$ que viam a forte pressão exercida pelas Ligas de Defesa Nacional para que o governo adotasse um posicionamento diante da política agressiva alemã, a revista Careta de 8 de abril de 1916 publicou uma sátira em que apareciam os dizeres: “O equilíbrio difícil. A artista: 'Se essas ligas continuam a me apertar as pernas, eu vou ao chão'" (CARETA, 1916, p. 1).

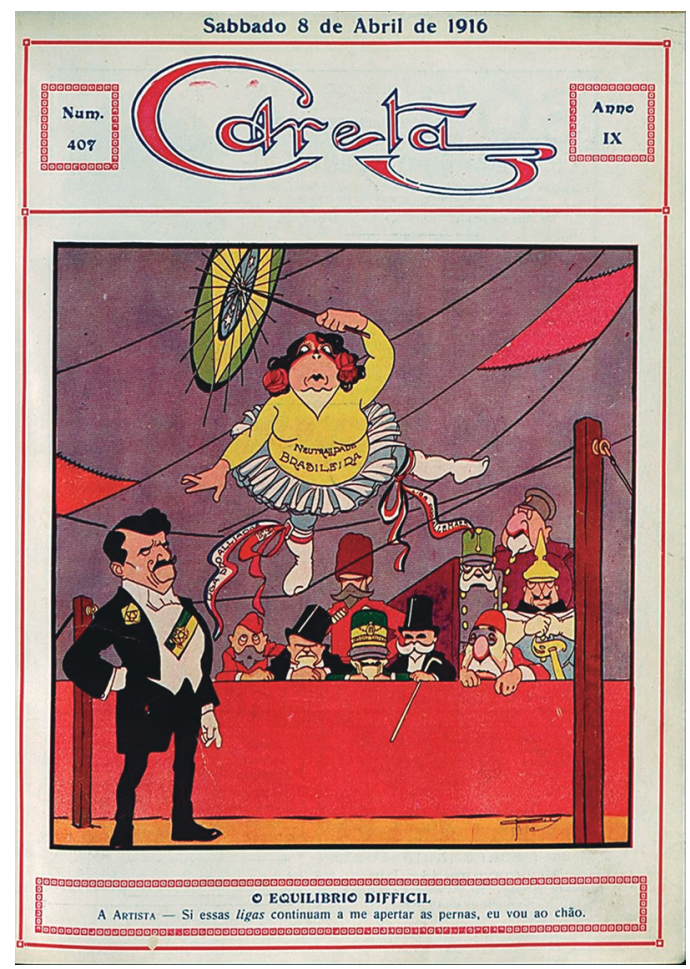


Nessa charge, aparece em primeiro plano, o presidente Venceslau Brás, apresentando o show, e ao fundo, as nações beligerantes, o seu significado indica a dificuldade de equilíbrio do governo não só diante das pressões internas, mas também externas que estava sofrendo para tomar um posicionamento mais efetivo a respeito da guerra.

Paralelo à Liga, um grupo de militares que haviam estagiado a alguns anos junto ao Exército alemão as ordens do Chanceler Paranhos e constituíam um núcleo denominado de "Jovens Turcos" por serem reformadores do pensamento militar brasileiro e juntamente com o ministro da Guerra, gen. Caetano de Farias, lutavam também pelo serviço militar obrigatório e por mudanças nas forças armadas em particular no Exército. ${ }^{4}$ Tais mudanças acabaram vindo entre os anos de 1915 e 1917, desde 1908 havia uma lei de sorteios para o serviço militar que somente começou a ser aplicada em 1916.

Desde que se iniciou o conflito, os estrangeiros, fossem alemães ou franceses que viviam no Brasil, começaram a fazer uma série de campanhas a favor de seus países de origem que estavam envolvidas no conflito, fazendo campanhas para arrecadar bônus de guerra e enviando dinheiro a seus países e regressando à Europa para alistarem-se por seus países de origem. Em cidades do sul do Brasil e em bairros de São Paulo ocorreram brigas e escaramuças entre imigrantes de países que lutavam entre si.

Mas havia intelectuais que se opunham à guerra, um dos mais ativos, se não o mais, foi Monteiro Lobato que chegou a declarar-se "germanofilo" ou pró-alemão apenas para irritar os jornais. Escreveu crô- nicas ridicularizando o que ele chamava de "Ufanismo Guerreiro" que era apregoado pela imprensa e por grande parte da intelectualidade brasileira, escreveu ainda duras declarações uma delas era uma crítica às reais obrigações do governo Venceslau Brás ao afirmar que:

Fala-se hoje em pátria mais do que nunca [...] com tudo isso, porem, está a retórica vã [...]. Programa patriótico, há um: sanear o Brasil. Guerra contra a Alemanha só há uma: sanear o Brasil. Saneá-lo antes que o estrangeiro venha faze-lo por conta e proveito próprios (MUNHOZ, 1980, p. 38).

Havia também oposição ao entusiasmo pela guerra entre as camadas populares, e surgiram manifestações entre esses setores tanto que em 26 de março de 1915, realizou-se uma assembleia no Rio de Janeiro, organizada por representantes de organizações sindicais e de jornais operários, em especial a Federação Operária do Rio de Janeiro, o resultado foi a criação de uma Comissão Popular de Agitação Contra a Guerra (DULLES, 1977, p. 37). Em São Paulo, os lideres trabalhistas e os diretores dos jornais proletários organizaram uma Comissão Internacional Contra a Guerra (DIAS, 1962, p. 289).

No dia $1^{\circ}$ de maio daquele ano, ocorreu na cidade de São Paulo, ao largo de São Francisco, uma grande concentração popular que reuniu em torno de 5.000 pessoas que traziam cartazes com os dizeres "Abaixo a guerra, queremos a paz", foi distribuído um manifesto intitulado de "Pela Paz", dirigido "aos trabalhadores e ao povo em geral" o texto do manifesto explicava que as origens do conflito era resultado das rivalidades existentes entre as grandes potências 
europeias por conta de suas políticas de expansão colonial (MUNHOZ, 1980, p. 39).

A situação da guerra na Europa tornou-se mais grave para as relações da Alemanha com os demais países, sobretudo os da América e em especial com o Brasil e os Estados Unidos ao estabelecer uma política de bloqueio contra a Inglaterra (ARAÚJO, 2005). Em 31 de janeiro de 1917, o ministro das relações exteriores da Alemanha Arthur Zimmermann notificou o governo brasileiro do estabelecimento do bloqueio alemão ao redor da costa da Inglaterra, França e Itália e na parte oriental do mar Mediterrâneo (BRASIL, 1917, p. 7).

$\mathrm{O}$ governo brasileiro não apoiava o bloqueio apesar de protestar rompendo relações comerciais com a Alemanha. Em 5 de fevereiro de 1917, o presidente dos Estados Unidos, Woodrow Wilson declarou o rompimento das relações com a Alemanha, mas o governo do presidente Venceslau Brás continuou mantendo o Brasil neutro.

Em 17 de fevereiro de 1917, as sátiras continuavam, e a revista Careta publicou mais uma sobre a neutralidade brasileira que dizia: “O super-neutro, Momo: 'Eu cá não ligo a batalhas de... lança pro fundo!'" (REVISTA CARETA, 1917.) A crítica da neutralidade brasileira se relacionava com o carnaval e a alusão às batalhas de lança-perfume durante o carnaval daquele ano e ao fato do governo brasileiro não se importar com os afundamentos de navios norte americanos que enfrentavam o bloqueio dos submarinos alemães.

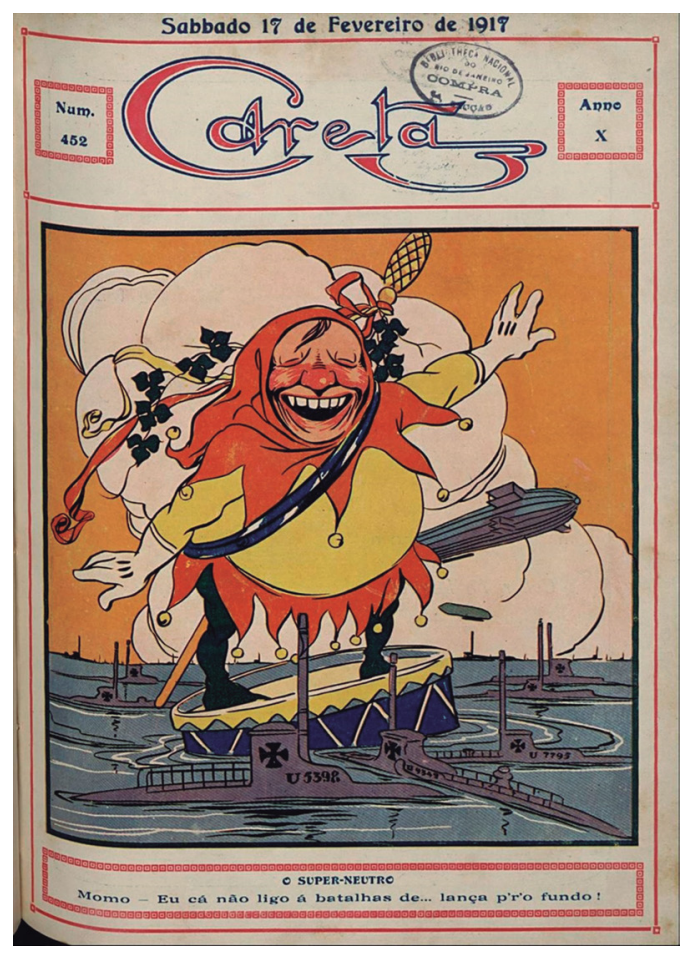

Com a determinação da Alemanha em estabelecer um bloqueio contra os países aliados e decretar seguidamente a guerra submarina sem restrições, a situação dos navios e das tripulações da Marinha Mercante brasileira que navegavam pelas águas europeias tornou-se perigosa.

Em 3 de abril de 1917, o navio mercante brasileiro Paraná navegava a 10 ilhas da cidade litorânea de Barfleur entre o canal da Mancha e a França, obedecendo a todas as exigências feitas, as embarcações de nações neutras em época de conflito, quando a noite e sem aviso prévio foi torpedeado causando a morte de 3 tripulantes (VINHOSA, 1990, p. 109). Oito dias depois o governo brasileiro rompeu as relações diplomáticas com a Alemanha. 
O presidente Woodrow Wilson, havia saudado com satisfação o rompimento da neutralidade brasileira, fato amplamente divulgado pela imprensa nacional. Provavelmente via como um alento à entrada do Brasil na guerra, pois era conhecida a sua capacidade naval, visto que havia feito há poucos anos uma grande reforma em sua marinha de guerra e continuava em processo de reestruturação, assim essa força poderia assumir as responsabilidades de patrulhamento do Atlântico Sul, o que aliviaria as responsabilidades dos Estados Unidos nos mares do Sul (ARAÚJO, 2005).

A 18 de outubro daquele ano, a Marinha Mercante brasileira sofreu um novo ataque, dessa vez foi o navio Macau de propriedade do Lloyd Brasileiro, era um dos navios alemães encampados pelo governo, recebeu tripulação brasileira de 26 homens foi carregado de café e cereais destinados à França, partiu do porto de Santos em 5 de setembro.

Com a chegada da notícia, ao Brasil, do torpedeamento do Macau e do salvamento da tripulação por um navio espanhol, o presidente Venceslau Brás encaminhou uma mensagem ao congresso nacional solicitando, a ocupação de um navio de guerra alemão que estava surto no porto de salvador desde 1914, a canhoneira Eber. A canhoneira tivera a missão de abastecer o cruzador auxiliar Cap Trafalgar de armamento munição e pessoal quando circulou pela costa do Brasil, pretendia-se ainda prender a sua tripulação, outra medida, era decretar a internação das tripulações dos 45 navios mercantes que haviam sido apropriados pelo governo (GAMA, 1982, p. 20).
A canhoneira Eber foi afundada pela tripulação, e os 45 navios mercantes foram evacuados, mas foi possível o governo verificar que dois terços deles estavam sabotados além de que todos eles estavam incluídos em uma espécie de "lista negra" dos aliados para apressamento, apesar disso, trinta deles foram fretados ao governo francês, e 15 ficaram a serviço do Brasil (MARTINS, 1997, p. 263).

Em 25 de outubro de 1917, o governo brasileiro reconheceu e proclamou o "estado de guerra iniciado pelo Império Alemão contra o Brasil" (ARAÚJO, 2005).

Quando do afundamento do Paraná, a população ficou agitada e atacou as firmas comerciais de propriedade de alemães na capital e nas principais cidades do Brasil, o que acabou criando uma situação delicada com a neutralidade brasileira.

Mas quando a guerra foi definitivamente declarada começou uma intensa agitação nacionalista sucederam-se "comícios patrióticos" que pediam a participação do Brasil na guerra e louvavam a atitude brasileira de apoiar os Aliados além de haver demonstrações contra a Alemanha. Alguns jornais e companhias alemães viram-se forçados a encerrar as suas atividades (DULLES, 1977, p. 61).

Mais uma vez Monteiro Lobato se fez presente, opondo-se ao que ele chamava de "nacionalismo guerreiro" e denunciava-o como uma forma de desviar a opinião pública dos verdadeiros problemas dos brasileiros: “[...] a precariedade da saúde pública e o caráter antidemocrático do governo presidencialista que não dava poderes à Câmara e ao Senado[...]" (MUNHOZ, 1980, p. 42). Com isso, afirmava que de forma unilate- 
ral o executivo governava o país cedendo a pressões externas.

No dia 17 de novembro de 1917, no mês seguinte, a declaração de guerra à Alemanha, o governo brasileiro decretou estado de sítio no Distrito Federal, Rio de Janeiro, São Paulo por serem regiões de intensa agitação operária e os estados do Paraná, Santa Catarina e Rio Grande do Sul por serem regiões de grande concentração de imigrantes alemães. $\mathrm{O}$ decreto foi aprovado quase por unanimidade, sendo apenas um dos parlamentares contrários: o deputado Maurício de Lacerda, que protestou afirmando que: “Os governantes não queriam agir contra os traidores, mas sim reprimir o operariado e suas lideranças mais expressivas"(MUNHOZ, 1980, p. 43).

De fato, Maurício de Lacerda afirmava que o estado de sítio mascarava outros interesses como o de esvaziar as manifestações operárias que vinham acontecendo já algum tempo e estavam importunando o governo do presidente Venceslau Brás.

O último navio atacado por submarinos alemães foi o do cargueiro Taquari fato ocorrido em 2 de janeiro de 1918 próximo ao litoral da Inglaterra, o barco foi canhoneado, morreram 8 membros da tripulação que tentavam escapar pelas baleeiras, o navio, contudo, conseguiu escapar a perseguição sendo conduzido pela tripulação até o porto inglês de Cardiff (MARTINS, 1997, p. 263).

Várias providências haviam sido tomadas, visando à defesa do litoral brasileiro contra a possibilidade do país sofrer com possíveis incursões de navios corsários alemães tal como havia ocorrido em agosto de 1914, mas o desafio maior seria a criação de uma força naval que pudesse levar a contribuição do Brasil à guerra na Europa, ou pelo menos ao largo de seu litoral, contra a ameaça de submarinos alemães.

De outro modo, Pandia Calogeras crítico realista da situação militar brasileira, e ministro dos negócios da guerra em 1919, não poupou críticas à situação beligerante em que se envolveu o país em 1918, pois segundo ele em termos de capacidade de combate às forças armadas estavam totalmente despreparadas, e os navios da Marinha estavam totalmente inoperantes, em relatório confidencial indicou a incapacidade tanto do Exercito quanto da Marinha (CALOGERAS, 1933, p. 35).

Seria um grande desafio fazer o país ter uma participação mais efetiva, contudo recairia sobre a marinha o fardo dessa missão.

\section{ADivisão Naval de Operações de Guerra - DNOG}

De 3 de setembro a 20 de novembro de 1917, aconteceu em Paris a Conferência Inter-aliada da qual o Brasil participou por meio do ministro Olinto de Magalhães que firmou o compromisso do país em contribuir com a guerra de três formas: enviando uma Divisão naval de operações de guerra que operaria onde a marinha inglesa achasse conveniente; segundo: o envio de um grupo de aviadores para treinamento e participação de futuras missões e finalmente de uma missão medica (VINHOSA, 1990, p. 133).

Desde outubro de 1917, foi concedida a autorização a oficiais brasileiros para estagiarem em navios da Marinha norte americana e vice versa, na mesma ocasião foi concedido 
o direito aos navios da marinha dos Estados Unidos sob comando do Almirante Caperton receberem carvão em Itaparica na Bahia.

O ministério das relações exteriores do Brasil já vinha trocando correspondência com o ministério das relações exteriores da Inglaterra no sentido de ser concretizada a oferta do governo brasileiro sobre a divisão naval, especificando que seriam dois cruzadores e quatro destróieres que operariam entre Dacar - São Vicente - Gibraltar (BRASIL, 1918, p. 198).

A Divisão Naval de Operações de Guerra ou DNOG como ficou mais conhecida teve a sua criação confirmada por um aviso confidencial do Ministro dos Negócios da Marinha Alexandrino Faria de Alencar dirigida ao Chefe do Estado maior da Armada, que dizia:

A vista da resolução do Governo de colaborar efetivamente na guerra que foi imposta pelo estado alemão, resolução tomada em conseqüência do acordo feito com os Governos dos países aliados, declaro-vos, para os devidos fins, que a Divisão em Operações de Guerra, que foi criada pelo Decreto desta data, devera se prepara para seguir para os mares europeus, a reunir-se à esquadra que for oportunamente Indicada (BRASIL, Aviso naval n 192-A, de 30/01/1918. SDM).

O aviso alertava, ainda, da providência em aprontar os navios que deveriam formar a Divisão. No mesmo dia outro aviso do Almirante Alexandrino foi dirigido ao Chefe do Estado Maior da Armada comunicando que a divisão seria composta pelos Cruzadores Bahia e Rio Grande do Sul e pelos contratorpedeiros Piauí, Rio Grande do Norte, Paraíba e Santa Catarina. Foi ainda assinado o decreto nomeando para o comando da Divi- são o Contra Almirante Pedro Max Fernando de Frontin.

Uma das primeiras providências do Contra Almirante Pedro de Frontin foi solicitar um navio tender de apoio, que serviria de base de operações inclusive transportando carvão, foi preparado o Belmonte que era um dos ex-navios alemães desapropriados que sendo armado passou a exercer também a tarefa de cruzador auxiliar, requisitou ainda um rebocador de alto mar e foi cedido o Laurindo Pitta. Com a criação dessa força, as três divisões que estavam patrulhando a costa do país ficaram sensivelmente reduzidas, pois tiveram que fornecer navios para a constituição da DNOG.

O pessoal que compôs a DNOG, salvo alguns oficias de estado maior, foram todos destacados pois compunham as tripulações dos navios que haviam sido destinados à força, a relação total dos componentes constava de 1.502 homens, sendo 75 oficiais da armada, 4 oficiais médicos, 50 oficiais maquinistas, 5 oficiais comissários, 1 farmacêutico, 1 dentista, 1 capelão, 1 submaquinista, 41 suboficiais, 43 mecânicos, 4 auxiliares de fiel, 702 marinheiros, 481 foquistas, 89 taifeiros, 1 padeiro e 3 barbeiros, dentre os marinheiros havia ainda uma banda de música composta por 27 militares (GAMA, 1982, p. 132).

\section{0 preparo da Divisão}

Ao ser determinado quais os navios iriam compor a DNOG, uma das primeiras providências do Contra Almirante Frontin foi ordenar o preparo e a atualização dos navios, quando pôde verificar que as dificuldades eram grandes, pois não havia nos 
arsenais os materiais necessários aos reparos e melhoramentos dos navios.

O Belmonte que foi transformado em cruzador auxiliar e tender da divisão demandou muito trabalho para ser transformado de navio mercante em um vaso de guerra para prestar apoio logístico à força.

Levou certo tempo até que os navios ficassem prontos e mesmo assim alguns ainda não saíram convenientemente preparados. A tarefa de atualização dos contratorpedeiros parecia ser mais fácil, mas não deixava de ser trabalhoso, como nos diz Silveira Leite:

Enquanto os engenheiros navais, mestres e operários do Arsenal e do Armamento reparavam as maquinas, caldeiras, canhões, torpedos e as suas instalações complementares, os oficiais e a guarnição do navio [...] procediam a uma extensa e minuciosa faxina de desmontagem e tratamento de todo o navio [...] o que valeu ao Piauí o jocoso apelido de "pinto sujo" (LEITE, 1961).

Os trabalhos nos cruzadores de igual forma foram dificultosos, pois esses apresentavam problemas nas turbinas de propulsão e naquela época esse tipo de maquinário ainda era experimental, fazendo com que parte de seus propulsores precisassem ser trocados, ${ }^{5}$ o que não podia ser feito no Brasil, pois não havia peças sobressalentes para esse tipo de máquina.

\section{Do litoral brasileiro ao litoral da África}

O Almirante Pedro de Frontin havia decidido que, à medida que ficassem prontos, os navios deixariam o Rio de Janeiro, os cruzadores seguiriam para Recife e os contratorpedeiros para Natal, onde aguardariam os trabalhos finais nas unidades restantes.
Os primeiros navios a seguirem essa determinação foram o Piauí e o Paraíba que deixaram o Rio de Janeiro em 07 de maio de 1918, largaram de suas boias de amarração e, depois de desfilarem pelo fundeadouro dos navios da Esquadra, as tripulações davam "vivas" e nos mastros tremulavam os sinais de "boa viagem" (LEITE, 1961).

No dia 09, foi a vez do Rio Grande do Norte que teve alguns problemas com suas máquinas, acabando por ser rebocado pelo Piauí até Salvador, onde já se encontrava o Paraíba. No dia 13 daquele mês, chegou o Santa Catarina.

Os cruzadores saíram do Rio de Janeiro no dia 11 de maio de 1918, o navio capitânia era o cruzador Rio Grande do Sul. No dia da partida estava no ancoradouro da Marinha o presidente Venceslau Brás, o Ministro da Marinha Alexandrino de Alencar, outros ministros e membros da liga de defesa nacional entre eles o Dr. Pedro Lessa que proferiu um discurso de despedida (GAMA, 1982, p. 141).

Os referidos navios chegaram ao porto de Salvador no dia 14 de maio, onde foram reunidos todos os componentes da Divisão, alguns serviços suplementares para melhorar a eficiência deles foram realizados a cargo da Companhia de Navegação Baiana, serviços de melhoria como de controle de fogo da artilharia combate a incêndio, vigilância e revisão de artilharia, nos torpedos e bombas antissubmarino (BRASIL, Circular da DNOG n 31, de 06/06/1918. SDM).

Ao mesmo tempo eram realizados incessantemente exercícios de todos os tipos desde tiro ao alvo, comunicações a lançamentos de torpedos, outra grande preocupação era a de uniformização dos métodos e proce- 
dimentos administrativos (BRASIL, Circular da DNOG n 34, de 13/06/1918. SDM).

Entre o mês de maio e meados de julho os navios permaneceram ao longo do litoral do nordeste em adestramentos deslocando-se entre Salvador, Natal e Recife, os dois últimos navios ao saírem do Rio de Janeiro foram o cruzador auxiliar Belmonte carregado de carvão e de peças sobressalentes que saiu dia 06 de julho de 1918, dirigindo-se a Recife, chegando dia 13 e o rebocador de alto mar Laurindo Pitta que saiu dia 08 daquele mês, indo direto para o ponto de encontro de todos os navios que era Fernando de Noronha.

O Contra Almirante Pedro de Frontin que havia marcado o dia 24 de julho para os navios encontrarem num ponto determinado para juntas seguirem até Fernando de Noronha na ordem do dia daquela data expressava a confiança na missão que teriam que cumprir, pois segundo ele a

[...] Divisão Naval representava a Marinha do Brasil nessa Grande Guerra. Essa Divisão representa, hoje, a contribuição das forças militares do Brasil na batalha. (BRASIL, Ordem do Dia da DNOG n 6, de 24/07/1918. SDM).

$\mathrm{O}$ encontro dos contratorpedeiros que vinham de Natal se deu com os cruzadores que vinham de Recife a 80 milhas da costa, e juntos seguiram em formatura chegando em Fernando de Noronha, em 26 de julho (LEITE, 1961). Até o dia 31 foram realizados os últimos preparativos para a partida definitiva da Divisão, os navios foram abastecidos de carvão, água e mantimentos, sendo resolvidos ainda alguns assuntos administrativos, como alterações no comando de alguns oficiais.
As instruções mais importantes da Divisão eram os que se relacionavam com as instruções para a viagem dados sobre o dispositivo de cruzeiro, de batalha e de entrada nos portos, táticas a serem usadas na caça aos submarinos, os procedimentos a serem adotados para o encontro com navios de superfície e salvamento de náufragos.

As missões de patrulha da Divisão já haviam começado desde a reunião da força em mar brasileiro e quando já estavam distante 324 milhas de Fernando de Noronha receberam um comunicado do comando naval inglês de que em sua rota havia sido assinalado a presença de um submarino alemão. O que não foi confirmado, mas foi averiguado pelos vigias do Rio Grande do Norte (BRASIL, Livro de quartos, do Rio Grande do Norte, de 04/08/1918. SDM).

Uma das maiores preocupações do Almirante Frontin era o cruzador Rio Grande do Sul que parou no meio do Atlântico para reparos nos motores em plena zona de perigo, ficando com dois contratorpedeiros para protegê-lo, o qual depois de reparado seguiu a toda velocidade para alcançar os demais navios.

Havia ainda o problema do consumo de combustível. As observações do Almirante Frontin era a de economizar carvão ao máximo uma das medidas era reduzir ao máximo a utilização de máquinas auxiliares para iluminação e os serviços sanitários, tudo devia ser de utilidade indispensável, deviam ter todo cuidado para não haver perda do vapor das caldeiras e utilizá-las da melhor forma possível.

Uma das maiores dificuldades era justamente a de abastecimento de carvão, água 
e mantimentos do navio tender Belmonte para os demais navios em pleno oceano, além de reparos de urgência, para tais manobras todos os navios paravam e os contratorpedeiros que ainda não haviam sido abastecidos começavam a descrever círculos em torno dos demais navios para protegê-los de possíveis ataques (GAMA, 1982. p.148).

Nas proximidades de Serra Leoa na costa da África, a divisão devia se encontrar com o encouraçado inglês Britania, capitânia da Divisão sob comando do Almirante Sheppard, houve um desencontro e alguns navios da DNOG estavam ficando sem carvão, foi marcado um novo encontro e o cruzador Rio Grande do Sul dirigiu-se até o novo ponto para encontrar o encouraçado Britania o que aconteceu na noite do dia 08 de agosto, na manhã seguinte toda divisão chegou a Freetown.

\section{A gripe espanhola assola a força naval brasileira}

Ao chegarem a Freetown, em Serra Leoa, os navios foram reabastecidos de combustível e alguns reparos foram feitos. No entanto, a cidade estava praticamente vazia por causa de uma epidemia de gripe que havia começado, e que ficou conhecida por gripe espanhola.

As tripulações acabaram tendo contato com a gripe, pois havia um navio inglês chamado Mantua que estava fundeado à pouca distância dos navios brasileiros, esse frequentemente dirigia-se para fora do porto, soube-se depois que o navio ia lançar em alto mar os corpos dos membros da sua tripulação que haviam morrido após terem contraído a gripe (LEITE, 1961).
A Divisão deixou Freetown às 11 horas do dia 23 de agosto de 1918, com destino a Dacar, no Senegal, tiveram um pequeno problema com o contratorpedeiro Piauí que enroscou a sua âncora em um cabo submarino, mas logo se livrou, a viagem de Freetown a Dacar durou três dias. A viagem foi realizada com muita dificuldade, com chuvas torrenciais, mar grosso, cerração, os navios tinham de navegar em formação e com máxima vigilância para se defenderem de possíveis ataques de submarinos ou navios alemães (BRASIL, Circular da DNOG n ${ }^{\circ} 49$, de 27/08/1918 SDM).

Na véspera da chegada a Dacar, na noite de 25 para 26 de agosto, a Divisão sofreu ataque de um submarino alemão que lançou um torpedo contra o cruzador auxiliar Belmonte. O submarino foi avistado pelos vigias do contratorpedeiro Rio Grande do Norte, do cruzador Bahia, e do rebocador Laurindo Pit$t a$, um marinheiro chamado Prado Maia que serviu como cabo na Divisão afirmou que:

[...] os dois primeiros navios deram o alarma de submarino à vista e abriram fogo sobre ele, que procurava imergir após haver lançado um torpedo contra o Belmonte [...] todos estavam acordados, as guarnições viveram instantes de angustiosa expectativa, aguardando quase sem respirar o impacto do torpedo, cuja esteira fosforescente era claramente observada [...] (GAMA, 1982, p. 151).

Os navios começaram a navegar em ziguezague, atirando contra o submarino e sobre a rota do torpedo na tentativa de atingi-lo, este passou resvalando o costado do Belmonte.

Embora vários dos navios da divisão tivessem aberto fogo e lançado bombas de 
profundidade sobre o submarino inimigo, o seu afundamento foi creditado ao Rio Grande do Norte, pois o marinheiro de $1^{a}$ classe artilheiro Lourenço Eduardo Eustáquio dos Santos se encontrava como vigia de prontidão no canhão principal de $101 \mathrm{~mm}$ do contratorpedeiro e foi quem primeiro abriu fogo por ordem do comandante.

Os canhões de $101 \mathrm{~mm}$ e de $47 \mathrm{~mm}$ do Rio Grande do Norte alvejaram o submarino sucessivas vezes que, desaparecendo, teve o seu rastro seguido pelo contratorpedeiro que lançou ainda bombas de profundidade no local de sua submersão, o mesmo submarino foi visto ainda pelo mecânico naval Franco Júnior, pelo cabo Severo Leal e pelo grumete Pires Bastos (BRASIL, Livro de quartos do Rio Grande do Norte, de 25/08/1918. SDM).

A perda do submarino foi confirmada pelo relatório do Almirantado britânico que indicava o desaparecimento de um submarino alemão que operava na rota da divisão brasileira e pelo comandante da base inglesa em Gibraltar Vice Almirante Heathcoat S. Grant.

Em 26 de agosto de 1918, pela manhã a Divisão entrou no porto de Dacar com os navios maiores atracando no quebra mar e os menores nas boias que existiam perto do atracadouro.

A Divisão iria passar poucos dias, apenas o tempo suficiente para a realização de trabalhos de limpeza dos cascos, reabastecimentos e para resolver um problema de propulsão dos motores do Rio Grande do Sul. Mas, no dia 06 de setembro quando eram planejadas as primeiras missões de patrulhamento até Gibraltar irrompeu uma violenta epidemia de "gripe espanhola", além de uma série de moléstias próprias da re- gião como o impaludismo e febres biliares, segundo o Almirante Frontin: “[...] alguns convalescentes ficaram com um grande abatimento moral, forma neurastênica que os torna incapaz de qualquer função diretiva [...]" (BRASIL, Ofício ao Comandante da marinha do Comandante da DNOG n ${ }^{\circ} 157$, Dacar, 26/09/1918 SDM.).

Mas a impressão maior foi deixada pela gripe espanhola, a gripe que se iniciou no cruzador Bahia pegou a tripulação que estava trabalhando com o carvão do navio com tal violência, que impediu a normalização das suas tarefas, passando a ser um navio hospital segundo Orlando Machado que era imediato do Rio Grande do Sul: "Os doentes caiam ardendo de febre, cobertos de suor, emplastados com a moinha do carvão, sem ter nem sequer quem os auxiliasse a tomar banho e mudar a roupa pois os poucos validos que lhes poderiam assistir nisso diminuíam hora a hora." (MACHADO, 1921).

Os toldos dos navios haviam sido retirados o que tornou a vida abordo mais difícil, pois o sol de Dacar era escaldante, os navios ficaram com noventa e cinco por cento de seu efetivo em completo estado de prostração.

De 10 a 20 de setembro, era essa a situação do Rio Grande do Sul e das demais belonaves, todos os compartimentos dos navios estavam ocupados por doentes da enfermaria, dos alojamentos ao quarto do Almirante Frontin encheram-se de doentes.

Ainda de acordo com Machado, a gripe tinha a seguinte evolução: "Cerca de três ou quatro dias depois de declarada a moléstia, vinha a tosse, vinha a expectoração sangüínea, vinha a congestão pulmonar: foi, 
durante dias e noites, o flagelo de um tossir convulsivo[...]" (MACHADO, 1921).

Houve mesmo casos de completo delírio por parte das tripulações como o de um marujo que estava em estado grave e conseguiu sair do hospital em Dacar acometido de uma espécie de delírio erótico, segundo Machado ele:

[...] dirigira-se para a espelunca mais próxima que conhecia. La chegando, entregara-se aos maiores excessos [...] teve ainda forças para vir abordo [...] Duas horas depois caíra na mais profunda prostração, insensível mesmo a varias injeções de éter e a repetidas fricções de álcool vindo a falecer depois de mais de seis horas de agonia (MACHADO, 1921).

A epidemia atacou não somente a Divisão, mas a todos os navios do Porto e a própria cidade de Dacar, que também sofria com a malária. Assim, em 11 de outubro, o Almirante Frontin comunicou ao Estado Maior da Armada por telegrama que a epidemia de gripe estava controlada, mas havia surgido a malária.

Ele havia solicitado também o envio de sais de quinino para o tratamento da gripe e reclamava que não haviam chegado a tempo, pois caso contrário poderia ter obtido por meio de troca de outros medicamento para tratamento preventivo até da malária (BRASIL, Ofício da DNOG ao Estado Maior da Armada, n 169, Dacar, 03/10/1918. SDM).

Os primeiros mortos foram enterrados em caixões; os outros, apenas foram atados em pedaços de tábuas, houve dias em que os mortos não podiam ser transportados até a lancha que fazia o recolhimento de cadáveres. Houve, pelo menos, um dia em que os mortos não foram recolhidos por ser um dia sagrado da religião muçulmana, a qual predominava no lugar.

No cemitério, foram sepultados 156 dos tripulantes, mas ainda houve mortes na tripulação pelas demais doenças e, posteriormente, no Brasil dos que voltavam, por conta da fraqueza em decorrência da gripe.

A Divisão estava envolvida com os problemas da gripe em sua pior fase quando o Almirantado britânico requisitou o envio de uma unidade a fim de auxiliar a força naval portuguesa que também estava passando pelo problema da gripe e operava próximo às ilhas de Cabo Verde, pois haviam assinalados submarinos alemães.

O único navio em condições de operar era o contratorpedeiro Piauí que teve a sua tripulação reforçada com marujos e oficiais ainda sadios das outras embarcações da DNOG. No dia 09 de setembro, o navio já contava com 20 gripados, ao chegar ao seu destino conseguiu atracar próximo à canhoneira portuguesa Beira que já tinha gripados a bordo. quando os brasileiros começaram a melhorar, os portugueses pioraram, o Piauí conseguiu concluir a missão que havia recebido até o dia 19 de outubro, quando regressou a Dacar (LEITE, 1961).

Os ingleses que de igual forma haviam sido atacados pela gripe tinham pressa em fazer a DNOG chegar a Gibraltar. Antes de partir o Almirante Frontin teve que pedir reforços ao EMA e teve que aguardar a chegada dos substitutos para ocupar o lugar dos falecidos, em $1^{\circ}$ de novembro, o Paraíba e o Piauí ainda deram caça a um submarino alemão em apoio a marinha francesa.

Em 3 de novembro, a DNOG deixou Dacar com destino a Gibraltar sem o cruza- 
dor Rio Grande do Sul, que apresentou sérios problemas em suas máquinas, retornando definitivamente ao Brasil. O cruzador Bahia passou a ser a capitania, porém deixou também o contratorpedeiro Rio Grande do Norte com problemas em seu eixo de transmissão dos motores, mas resolvido o seu problema alcançou a Divisão em Gibraltar.

O cruzador auxiliar Belmonte foi dispensado para levar um carregamento de trigo que foi fretado pelo governo francês, o rebocador de alto mar Laurindo Pitta também foi dispensado e viajou de volta ao Brasil (MARTINS, 1997 p. 273).

A Divisão após deixar Dacar avistou em sua frente uma longa esteira de espuma branca que confundiu as tripulações por imaginarem que se tratava de um periscópio de submarino. O Bahia abriu fogo seguido pelos demais navios. Logo depois verificaram que se tratava de um cardume de toninhas o que acabou dando motivos a piadas por parte dos homens da Divisão. ${ }^{6}$

Em viagem a Gibraltar, a Divisão iria encontrar-se com o encouraçado Britania capitania da força inglesa o encontro estava marcado para o dia 9 de novembro e, em caso de atraso, dia 10, ao longo da viagem, as estações radiotelegráficas francesas chamaram diversas vezes a Divisão brasileira que não atendeu em respeito ao silêncio internacional de rádio.

Alertados pelos chamados contínuos de rádio dos franceses, três submarinos alemães concentraram-se próximo ao estreito de Gibraltar e sendo o Britania o primeiro a chegar foi torpedeado por um submarino e afundou.

A Divisão entrou em Gibraltar no dia 10 de novembro ainda a tempo de ver se- pultamento das vítimas do Britania.No dia seguinte. foi assinado o armistício entre a Alemanha e os aliados que deu fim a Grande Guerra (MARTINS, 1997, p. 273).

A DNOG foi convidada a participar das festividades de comemoração pela paz promovida pelos países vitoriosos. Assim, antes do retorno ao Brasil, a Divisão deixou Gibraltar em 20 de janeiro de 1919 e foi à Inglaterra, à França, a Lisboa, retomando a Gibraltar para logo em seguida entrar no mediterrâneo e ir até a Itália, com a missão "levar a bandeira do Brasil às nações amigas".

Ao retornar para Gibraltar a DNOG partiu definitivamente para o Brasil, chegando a Recife no dia 23 de maio de 1919, e ao Rio de Janeiro no dia 9 de junho. A recepção em Recife havia sido calorosa, e no Rio de Janeiro os marinheiros haviam sido saudados por todas as embarcações da baía (GAMA, 1982, p. 160). E por ordem do ministro da marinha, pelo Aviso naval $n^{\circ} 3.053$, de 25/06/1919 a DNOG foi dissolvida.

\section{Conclusão}

Com a chegada da Primeira Guerra Mundial, em 1914, o governo brasileiro enfrentou divergências na sociedade em suas diversas camadas e teve que arcar com as dificuldades de manter um equilíbrio entre a neutralidade e o dilema em declarar guerra à Alemanha por conta da pressão que sofria interna e externamente.

A Marinha brasileira, apesar de contar com navios relativamente novos, não estava atualizada e nem pronta para o desafio de enfrentar a Alemanha nos mares, por falta de um parque de manutenção permanente, 
que com tecnologia própria que não dependesse de sobressalente vindos da Europa e mesmo a protoindustrialização que aqui surgiu, não permitia fazer mais que o trivial: para lançar os navios na missão de defender a costa do Brasil de forma satisfatória.

Além de que quando a guerra estourou as reformas não havia acabado o que representava um paradoxo, pois enquanto as primeiras unidades não haviam ainda sido atualizadas, ela continuava recebendo navios em 1914 sem atualizar os que chegaram em 1910.

O maior desafio ainda veio por conta do compromisso de assumir, de forma mais efetiva, o combate aos submarinos alemães ao largo do litoral da África. O Brasil esteve sob pressão de outros países que julgavam que esse poderia arcar com a tarefa de patrulhar os mares do sul ao longo daquela costa por avaliarem que a sua marinha estava suficientemente preparada para a missão. Com esse julgamento aliviavam as suas próprias responsabilidades. O problema dos navios que foram atualizados às pressas e que haviam partido para a sua missão com sérios problemas de manutenção era também agravante e representava de igual forma os limites da logística naquela época.

Para a missão que a marinha brasileira foi destacada ficaram claras também as deficiências sanitárias em que a divisão ficou sujeita por conta da burocracia, pois sob a situação de epidemia, as solicitações de medicamentos não eram atendidas de imediato para sanar a gripe espanhola.

Por fim, com a conclusão da guerra, as perdas de vidas humanas e as perdas materiais do país jamais foram compensadas a altura dos esforços e o país teve que amargar prejuízos financeiros por conta do bloqueio, dos afundamentos e do não pagamento das indenizações previstas pelo tratado de Versalhes.

A participação do Brasil na política externa no início do Século XX e a sua participação na Primeira Guerra Mundial, sempre foram vistos como algo de irrelevante significância dentro da conjuntura da história brasileira. No entanto, podemos verificar que embora tenha sido desafiado pela Alemanha, o país se viu compelido pela intensa pressão de meios internos e externos a ingressar em uma guerra que não era sua.

Tendo ainda, o país que assumir uma responsabilidade que também não era sua, entregando essa tarefa a um grupo de militares que acreditavam serem capazes de levar a termo a missão a eles confiada, realizaram-na diante das dificuldades. Só não sabiam que pagariam um preço tão caro, alguns pagaram com a vida para se tornarem um mero lembrete da participação brasileira em um dos mais importantes momentos da história contemporânea.

\section{Abstract}

This article seeks to address on the mobilization of society and the Brazilian naval display in 1918, as a response of President Wenceslau Brás German aggression against the Brazilian merchant ships in 1917, in addition to observing which were the measures taken towards organize an effective naval force called Naval Operations Division War (DNOG) to patrol the Atlantic coast of North Africa.

Keywords: World War First. Mobilization. Brazilian Navy. 


\section{Resumem}

Este artículo trata de abordar en la movilización de la sociedad y el aparato naval brasileña en 1918, como una respuesta del presidente Blaise Wenceslau agresión alemana contra los buques mercantes brasileños en 1917, además de observar que fueron las medidas adoptadas para organizar una fuerza naval eficaz llamada de División Naval de Operaciones de Guerra (DNOG) para patrullar la costa atlántica del norte de África.

\section{Palabras clave: Primera Guerra mundial.} Movilización. Marina de Brasil.

\section{Notas}

1 Para um dos entendimentos a respeito do conflito e os desenlaces inicias da Primeira Grande Guerra ver: TUCHMAN, Barbara. Os Canhões de Agosto. Rio de Janeiro: Objetiva, 1994.

2 O serviço militar no início da República não era obrigatório somente depois das reformas idealizadas por Paranhos foi instituído o sistema de sorteios até que Olavo Billac iniciou, entre os anos de 1915 e 1916, a campanha pelo serviço militar obrigatório, sendo oficializado em 1918 pelo Art. 93 da constituição.

3 Havia duas importantes publicações a Careta e a Fon Fon, a primeira através de charges fazia críticas à política de neutralidade e a influência exterior que o país sofria para participar do conflito; a revista Fon Fon era a mais comprometida com a propaganda do governo.

4 Jovens turcos é uma alusão ao grupo de militares turcos liderados por um oficial chamado Mustafa Kemal que liderou um amplo movimento de reformas políticas na Turquia.

5 O maquinário desses cruzadores era constituído de uma tubulação que alimentavam uma peça chamada de condensador que por sua vez compunha a turbina que fornecia força a navio.

6 Na imprensa brasileira, o ocorrido também gerou uma serie de anedotas escritas por jornalistas que fizeram citações sobre o fato em que chamaram de: "A guerra das toninhas" ou "A batalha das toninhas".

\section{Referências}

ARAÚJO, Johny Santana de. A construção do Poder Naval brasileiro no início do século XX: dos programas navais à grande guerra (19041917). Navigator. Subsídios para a história marítima. Rio de Janeiro, v. 1, n. 2, p. 69-86, dez. 2005. Disponível: <http://www.revistanavigator.com.br/navig2/art/N2_art5.pdf>. Acesso em: 22 fev. 2013.

BUENO, Clodoaldo. Política externa da Primeira República: os anos de apogeu (1902 a 1918). São Paulo: Paz e Terra, 2003.

CALOGERAS, João Pandia. Problemas de Administração. São Paulo: Companhia Editora Nacional, 1933.

DIAS, Everardo. História das lutas sociais no Brasil. São Paulo: Edaglid, 1962.

DULLES, John W. Foster. Anarquistas e Comunistas no Brasil, 1900 - 1935. Rio de Janeiro: Nova Fronteira, 1977.

GAMA, Arthur Oscar S. da. A Marinha do Brasil na primeira guerra mundial. Rio de Janeiro: Capemi, 1982.

LEITE, Jorge da Silva. O contratorpedeiro Piauí In: SIMPÓSIO SOBRE A PARTICIPAÇÃO DA MARINHA NA PRIMEIRA GRANDE GUERRA, 1961, Rio de Janeiro. Discurso... Rio de Janeiro: SDGM, 1961. Não paginado.

MACHADO, Orlando M, Nossa Hecatombe em Dakar. Boletim do Clube Naval n 12, mar. 1921. SDM. 1921. Não paginado.

MARTINS, Hélio Leoncio. A participação da Marinha do Brasil na Primeira Guerra In: História Naval Brasileira. Rio de Janeiro: SDM, Vol. $\mathrm{V}, \mathrm{t}$. IB, 1997.

MUNHOZ, Fernando. Reflexos da Guerra Europeia. Coleção nosso século. São Paulo: Abril Cultural, 1980, $\mathrm{n}^{\circ} 33$.

TAVARES, Aurélio Lyra. Brasil-França: ao longo de 5 Séculos, Rio de Janeiro. Bibliex, 1979. 
TUCHMAN, Barbara. Os Canhões de Agosto. Rio de Janeiro: Objetiva, 1994.

VINHOSA, Francisco Luiz Teixeira. O Brasil e a Primeira Guerra Mundial, Rio de Janeiro, IHGB, 1990.

\section{Fontes}

BRASIL. Ministério de Estado das Relações Exteriores. Relatório, 1917, Impr. Nacional, 1917, Arquivo Nacional (AN)

. Ministério de Estado das Relações Exteriores. Relatório, 1918, Impr. Nacional, 1918, (AN)

. Ministério de Estado dos Negócios da Marinha, Aviso naval n 192-A, de30/01/1918. Serviço de Documentação da Marinha (SDM).

Ministério de Estado dos Negócios da Marinha, Circular da DNOG $n^{\circ} 31$, de 06/06/1918. SDM.

Ministério de Estado dos Negócios da Marinha, Circular da DNOG $\mathrm{n}^{\circ} 34$, de 13/06/1918. SDM.

- Ministério de Estado dos Negócios da Marinha, Ordem do Dia da DNOG n 6, de 24/07/1918. SDM.

. Ministério de Estado dos Negócios da Marinha, Livro de quartos, do Rio Grande do Norte, de 04/08/1918. Não paginado. SDM.

Ministério de Estado dos Negócios da Marinha, Circular da DNOG $\mathrm{n}^{\circ} 49$, de 27/08/1918 SDM.

. Ministério de Estado dos Negócios da Marinha, Livro de quartos, do Rio Grande do Norte, de 25/08/1918. SDM.

Ministério de Estado dos Negócios da Marinha, Ofício ao Comandante da marinha do Comandante da DNOG $n^{\circ} 157$, Dacar, 26/09/1918 SDM.
. Ministério de Estado dos Negócios da Marinha, Ofício da DNOG ao Estado Maior da Armada, n 169, Dacar, 03/10/1918. SDM.

REVISTA CARETA. Rio de Janeiro: Kosmos, n. 407. fev. 1917. Indicação complementar. Biblioteca Publica Benedito Leite.

Biblioteca Nacional (BN) Disponível em: 17 fev. 1917. Disponível em: <http://objdigital.bn.br/acervo_digital/div_periodicos/ careta/careta_1917/careta_1917_452.pdf >. Acesso em: 23 mar. 2013. 